\title{
Zu diesem Heft
}

In den vergangenen dreißig Jahren ist die Auflage der deutschen Bistumsblätter kontinuierlich zurückgegangen. Betrug die Gesamtauflage 1963 noch 2,45 Mio., so sank sie bis 1995 auf 1,29 Mio. Eine Trendwende ist nicht in Sicht. Die vom Institut für Demoskopie Allensbach durchgeführte umfangreiche Feldbefragung zur Situation der Bistumspresse sowie die von Hans Mathias Kepplinger vorgelegte Inhaltsanalyse haben die schwierige Lage der Bistumszeitungen unmißverständlich aufgedeckt. Die wichtigsten Ergebnisse aus beiden Studien wurden im vorigen Heft von Communicatio Socialis veröffentlicht.

Auch dieses Heft ist in wesentlichen Teilen noch einmal dem Thema Bistumspresse gewidmet. So weist Michael Schmolke in seinem Beitrag nach, daß der gegenwärtige krisenhafte Befund der Bistumszeitungen sich seit vielen Jahren klar abgezeichnet hatte und auch entsprechend bekannt war.

Unter der Rubrik "Zur Debatte" veröffentlicht Communicatio Socialis sieben unterschiedliche Stellungnahmen bzw. Meinungsäußerungen zur Zukunft der Bistumspresse, die die Redaktion aus Anlaß der Allensbach-Studie und der Inhaltsanalyse von H. M. Kepplinger erbeten hatte. Es soll an dieser Stelle nicht verschwiegen werden, daß längst nicht alle von der Redaktion angefragten Autoren bereit oder in der Lage waren, sich im Anschluß an diese beiden Studien zu den Zukunftsperspektiven der Bistumspresse zu äußern.

Erweitert wird der Debattenteil noch durch knappe Auszïge aus einem neu erschienenen Buch, in dem ehemalige katholische Chefredakteure sich zur Zukunft der Kirchenzeitungen äußern.

Ergänzend zum Themenschwerpunkt 'Bistumspresse' informiert Matthias Müller in einem zweiten Beitrag über die Entstehung und die Entwicklung der schweizerischen ökumenischen Zeitschrift „aufbruch Forum für eine offene Kirche“. Die Zeitschrift wurde 1988 als Reaktion auf die umstrittene Einsetzung von Wolfgang Haas als Weihbischof des Bistums Chur mit dem Recht auf Nachfolge gegründet.

Im Berichtsteil kommentiert und dokumentiert Reinhold Zzvick die Filmempfehlungsliste des Päpstlichen Medienrates. In einem weiteren Bericht referiert er über die erste Tagung eines von der evangelischen Akademie Hamburg gegründeten „Arbeitskreises Populäre Kultur und Religion".

Es folgt die Veröffentlichung von zwei Referaten, die im März 1996 auf einem Seminar der britischen Advertising Association gehalten 
wurden, und in denen über den sog. ,V-Chip' ( $v=$ violence) berichtet wird. Dabei handelt es sich um einen in ein Fernsehgerät einbaubaren Chip, der all jene Gewaltszenen ausblendet, die auf den Filmen vorher markiert wurden.

Abgeschlossen wird der Berichtsteil mit einem kurzen Rückblick auf die Arbeit des päpstlichen Medienrates.

Helmuth Rolfes 